\title{
AUTORES Y PARTÍCIPES EN EL TRÁFICO DE SUSTANCIAS ILÍCITAS... ¿DELINCUENTES O ENEMIGOS?
}

\author{
PERPETRATORS AND PARTICIPANTS IN THE DRUGS TRAFFICKING: \\ OFFENDERS OR ENEMIES?
}

Christian SCHEeCHLeR ${ }^{1}$

\begin{abstract}
Resumen:
El planteamiento teórico del alemán Günther Jakobs sobre el Derecho penal del enemigo ha sido analizado y criticado constantemente durante la última década. La utilización del concepto enemigo se ha generalizado en su uso, sin embargo, en muchas ocasiones este no es fiel a lo planteado por el autor. En específico, cuando se aborda el macrotema del narcotráfico, se considera a todos quienes participan en este mercado ilícito como enemigos, avalando un tratamiento de choque que pone en jaque la protección de los derechos humanos. En las siguientes líneas se intentará abordar conceptualmente la postura planteada por Jakobs, para determinar si su noción de enemigo abarca a todos los partícipes del tráfico de sustancias ilícitas o si bien corresponde hacer una o más diferenciaciones, con el objetivo de, dentro de la misma línea de pensamiento del alemán, y en sede político-criminal, darle un tratamiento diversos a quienes responden a los parámetros del concepto enemigo frente a quienes quedan al margen.
\end{abstract}

Palabras clave: Derecho penal del enemigo, enemigos, narcotráfico, Jakobs.

\begin{abstract}
:
The theoretical position of Günther lakobs on the criminal law of the enemies has been analyzed and constantly criticized during the last decade. The use of the enemy concept has been generalized, however, in many occasions this it is not faithful to that outlined by the author. In specific, when this topic is approached fears of the drug traffic, it is considered all who participate in this illicit market as enemies, endorsing a crash treatment that it puts in check the protection of the human rights. In the following lines, it will be tried to approach the posture outlined by Jakobs conceptually, to determine if their enemy notion embraces all the participants of the traffic of illicit substances or although corresponds to make an or more differentiations, with the objective of, inside the same line of thought of german, to give a diverse treatment to those who respond to the parameters of the enemy concept in front of who it is to the margin.
\end{abstract}

Key words: Criminal law of the enemy, enemies, drugs traffic, Jakobs.

1 Abogado y Licenciado en Ciencias Jurídicas, Universidad Católica de Temuco. Diploma de Estudios Avanzados DEA en Derecho penal por la Universidad de Deusto, España. Profesor de la Escuela de Derecho de la Universidad Católica del Norte, Antofagasta. Correo: cscheechler@ucn.cl 


\section{Introducción}

Es ya un lugar común divinizar o demonizar a Günther Jakobs cuando hablamos del Derecho penal del enemigo (DPE). Se sostiene por una parte que ha revitalizado el discurso dogmático de fines del siglo XX y principios del XXI, mientras que sus detractores sostienen que sus ideas minan las bases de un Derecho penal garantista, centrado en un Estado social democrático de derecho más que en un Estado policial.

Las ideas del jurista alemán han trascendido las fronteras de su país y se han instalado en el discurso dogmático, filosófico y político-criminal. Incluso, como no, ha sido recepcionado por los docentes de Derecho penal, y ya es posible encontrar tesis, trabajos o ponencias sobre las ideas del alemán, atacándolo en la mayoría de los casos, defendiéndolo en los menos.

El Derecho penal del enemigo, como construcción filosófica, jurídica y política criminal, ha sido esgrimido para fundamentar la lucha contra la criminalidad moderna, en la que las conductas delictivas asociadas al tráfico de drogas y estupefacientes cumplen un papel central. Sin embargo, los discursos vacíos o simplemente aproximativos pueden no dar fe sobre lo realmente propuesto por Jakobs, otorgando un fundamento medianamente incorrecto a las medidas jurídico-penales que se quieran justificar.

Estas ideas sueltas buscan aproximarse al concepto de enemigo que ha utilizado Jakobs en su obra, para determinar cómo ha sido recepcionado por la dogmática penal moderna y la política criminal, y de qué manera esto impacta en la determinación de quienes son los enemigos penalizados por su participación en los hechos delictivos relativos al tráfico de drogas. No es una crítica ni un respaldo al DPE ni a su concepto de enemigo.

\section{Orígenes del enemigo}

Es el mismo Jakobs quien distingue en la filosofía jurídica diferentes conceptos de enemigo. Por una parte, una posición más extrema, como la de Rousseau o Fichte, que consideran enemigos a todos los delincuentes, y por otra, el enfoque moderado de Hobbes o Kant.

El concepto de enemigo -que sugiere un ente disociado al ser social-puede encontrar sus primeras ideas en los tiempos modernos en la criminología lombrosiana, que distingue al enemigo como un ser anormal, reconocible por características somáticas y síquicas especiales, que lo hacen distinto del ser humano normal. Se habla de 
un delincuente nato ${ }^{2}$. Basta darle una somera revisión a las ideas de Lombroso sobre la prostituta, el artista o el anarquista, por ejemplo. Sobre la primera en particular sostiene que "la prostitución es el equivalente de la criminalidad en la mujer, o sea, la forma específica bajo la que se manifiesta la degeneración de esta" ${ }^{3}$, y elabora un perfil fisiológico de la prostituta, de acuerdo a su capacidad craneana, orbital o ángulo facial mínimo, entre otros factores. Habla Lombroso de las prostitutas natas, marcadas no por características lascivas, sino que por su locura moral ${ }^{4}$. Además, señala el autor $-y$ esto no deja de ser curioso-, la prostituta congénita es altamente "glotona".

Esa criminología, cuyo centro de estudio es el delincuente nato o patológico, enemigo de la sociedad, ha dado un paso al costado frente a aquella que se preocupa del delincuente común, mundano y oportunista, que hoy está más cerca de la escena de investigación y de quienes diseñan las políticas públicas, y que al mismo tiempo es más coherente con el Estado social y democrático de derecho, que mantiene a la igualdad como principio básico del ordenamiento jurídico. Según Garland, este cambio de paradigma ha permitido la inclusión del análisis económico en la criminología moderna, cuya ponderación de costo-beneficio se contrapone a quienes diseñan políticas del tipo tolerancia cero, que confían profusamente en el poder intimidatorio que la aplicación de la pena tenga en el delincuente no nato. La lógica institucional del costo-beneficio de las políticas públicas -en nuestro caso contra la droga- se contrapone a la política pública del ataque al enemigo ${ }^{5}$.

Este nueva visión del delincuente se asocia a la Escuela Liberal Clásica, de la que surge una serie de principios importantes para el Derecho penal, entre los que se cuenta el principio "del bien y del mal", según el cual el delito constituye un daño para la sociedad, y la persona del delincuente se representa como un elemento negativo y disfuncional del sistema social, o sea, el mal, mientras que la sociedad encarna el bien ${ }^{6}$. Este Derecho penal se ve expresado en los códigos penales de la segunda mitad del siglo XIX -como el chileno-y en muchos del siglo XX, teniendo como único bache los códigos y leyes especiales de los regímenes totalitarios del siglo XX, para quienes se consideraban "enemigos" del pueblo. Curiosamente, estos códigos revestían sus atrocidades con los principios básicos del Derecho penal liberal garantista.

En la actualidad, la tendencia político-criminal predominante aboga por un Derecho penal máximo, punitivista, ciertamente consolidado -desde la perspectiva pú-

2 En Schilling Fuenzalida, Mario, El nuevo Derecho penal del enemigo, Ed. Librotecnia, Santiago, 2010, p. 32.

3 Peset, Mariano; Peset, José Luis (Estudio preliminar), Lombroso y la escuela positivista italiana, Ed. C.S.I.C., Madrid, 1975, p. 621.

4 Peset, obr. cit. p. 646.

5 Garland, David, La cultura del control. Crimen y orden social en la sociedad contemporánea, Ed. Gedisa, Barcelona, 2005, p. 304.

6 Aclara, como es del caso, que corresponde a una perspectiva ética, no jurídica. Schilling, obr. cit. p. 40. 
blica- como la mejor y más barata herramienta del combate contra la delincuencia ${ }^{7}$. Dentro de este marco, encontramos una tendencia que considera al Derecho penal como instrumento de estabilización de la norma jurídica en particular y del ordenamiento jurídico en general ${ }^{8}$.

Cuando un delincuente comete un hecho de relevancia penal, entrega un mensaje comunicativo de desvalor contra la norma, el que a su vez es anulado por la pena como contramensaje de vigencia del ordenamiento normativo (prevención general positiva). Jakobs, sobre las ideas de Luhman, es uno de los más importantes exponentes de esta tendencia. Entre sus críticos, Gomes y Bianchini estiman que este es un discurso dirigido al público en general, a la masa, y que termina siendo la explotación de la ignorancia del hombre común, que acaba confiando en este discurso de mayor seguridad ${ }^{9}$. Bajo esta tendencia se esboza el Derecho penal del enemigo, un Derecho penal de segunda o tercera velocidad, casi un No-Derecho, como indica Schilling ${ }^{10}$.

\section{3. ¿Qué es el Derecho penal del enemigo?}

Para Cancio Meliá se trata de determinados sectores legislativos que normalmente tienen por objeto la delincuencia organizada, la delincuencia sexual reincidente o habitual, o el terrorismo, entre otras materias, y que constituyen el resultado de la fusión entre el Derecho penal simbólico y el clima crecientemente punitivista que existe en el debate político en relación con ciertas materias ${ }^{11}$.

\footnotetext{
Un resumen de ideas en Silva Sánchez, Jesús María, La expansión del Derecho penal, Ed. Civitas, Madrid, $2^{a}$ ed. revisada y ampliada, 2001, pp. 20 y ss.

8 Véase, entre otros, García Martín, Luis, El horizonte del finalismo y el Derecho penal del enemigo, Ed. Tirant lo Blanch, Valencia, 2005. Para una panorámica general, Montealegre Lynett, Eduardo (coord.) El funcionalismo en el Derecho penal. Libro homenaje al profesor Günther Jakobs, Ed. Universidad Externado de Colombia, Bogotá, 2003. Obras básicas e imprescindibles: Luhmann, Niklas, Sociedad y sistema, la ambición de la teoría, Ed. Paidós, Barcelona, 1997; y Luhmann, Niklas, Complejidad y modernidad de la unidad a la diferencia, Ed. Trotta, Madrid, 1998; para la posición de Jakobs, véase, entre otras presentes en este trabajo, Jakobs, Günther, Sociedad, norma y persona en una teoría de un Derecho penal funcional, Ed. Civitas, Madrid, 1996.

9 Seguridad entendida como la "expectativa que podemos razonablemente tener de que no vamos a ser expuestos a peligros o ataques a nuestros bienes jurídicos más preciados por otras personas". Muñoz Conde, Francisco, El nuevo Derecho penal autoritario, en De Toledo y Ubieto, Emilio, Estudios penales en recuerdo del profesor Ruiz Antón, Ed. Tirant lo Blanch, Valencia, 2004, p. 807. Las críticas, véase en Gomes, Luis Flávio; Bianchini, Alice, Derecho penal del enemigo y los enemigos del Derecho penal, en Cancio Meliá, Manuel, Derecho penal del enemigo. El discurso penal de la exclusión, Ed. Edisofer, Madrid, 2006, p. 594.

10 Schilling, obr. cit. p. 51.

11 Jakobs, Günther; Cancio Meliá, Manuel, Derecho penal del enemigo, Ed. Civitas, Madrid, 2001, pp. 59 y ss. Muñoz Conde agrega a modo de enumeración no taxativa, y en el contexto europeo, la inmigración ilegal. Muñoz Conde, Francisco, obr. cit. p. 804.
} 
Jakobs no es el primero en utilizar el concepto de Derecho penal del enemigo, pero sin duda es quien lo ha puesto en el centro del debate penal moderno. Para Polaino, Jakobs es su máximo teórico, quien acuñó el concepto, pero no las normas ni los elementos básicos de la postura, como el propio concepto de enemigo ${ }^{12}$. Ya el mismo Mezger se refería a ciertos "grupos especiales de determinadas personas, como por ejemplo, los delincuentes por tendencia", que estarían regidos por un Derecho penal distinto al de la generalidad. O sea, algo así como enemigos sujetos a un Derecho penal para ciudadanos no comunes. Más claro queda el concepto cuando lo entendemos en su contexto: un proyecto de ley redactado por el jurista para el régimen nazi en 1943. Este proyecto buscaba combatir "extraños a la comunidad", y contenía sanciones o medidas de seguridad como reclusión indefinida en campos de concentración, esterilización o castración para los homosexuales, bajo el argumento de la seguridad presente y futura del pueblo ${ }^{13}$.

Volviendo a Jakobs, entre quienes lo han estudiando existe consenso en el hecho de que existe un "primer Jakobs", menos potente en el discurso sobre el enemigo, y que se encuentre cronológicamente ubicado entre el año 1985 y el término del milenio. Sobre el año 2000 en adelante surge un "segundo Jakobs", consagrando su pensamiento en el libro Derecho penal del enemigo, publicado en conjunto con el español Cancio Meliá.

El Derecho penal del enemigo de Jakobs se caracteriza por los siguientes elementos $^{14}$ :

12 Polaino Navarrete, Miguel; Polaino-Ürts, Miguel, Derecho penal del enemigo; desmitificación de un concepto", en Cancio Meliá, Manuel; Gómez-Jara Díez, Carlos (coords.), Derecho penal del enemigo. El discurso penal de la exclusión, Ed. Edisofer, Madrid, 2006, p. 630. En el mismo sentido, véase Acedo Quezada, Octavio, ¿Resurgimiento del Derecho penal autoritario? A propósito de una denominación", en AA. VV., Homenaje a Ricardo Franco Guzmán 50 años de vida académica, Ed. Instituto Nacional de Ciencias Penales, México D.F., 2008, pp. 13 y ss. Pastor, en tanto, incluso le resta importancia a lo propuesto por Jakobs, señalando que nada ha cambiado realmente desde que Jakobs (el segundo) entró fuertemente en escena con el cambio de siglo. Pastor, Daniel, El Derecho penal del enemigo en el espejo del poder punitivo internacional, en Cancio Meliá, Manuel; Gómez-Jara Díez, Carlos (coords.), Derecho penal del enemigo. El discurso penal de la exclusión, Ed. Edisofer, Madrid, 2006, p. 517.

13 Muñoz Conde, Francisco, Edmund Mezger y el Derecho penal de su tiempo, Ed. Tirant lo Blanch, Valencia, $4^{\text {a }}$ ed. 2003, p. 242. Esto trajo repercusiones y discusiones "privadas" entre Muñoz Conde y el propio Jakobs. Según narra el primero, el autor alemán habría escrito una carta a propósito de la publicación de Muñoz Conde sobre Mezger, calificando la interpretación del autor español como una "absurdidad". Más detalles en Muñoz Conde, Francisco, De nuevo sobre el Derecho penal del enemigo, en Velásquez Velásquez, Fernando (coord.), Derecho penal liberal y dignidad humana. Libro homenaje al Doctor Hernando Londoño Jiménez, Ed. Temis S. A., Bogotá, 2005, pp. 407 y ss.

14 Schilling, obr. cit. p. 56. Un ensayo sobre las características en Víquez, Karolina, Derecho penal del enemigo. ¿Una quimera dogmática o un modelo orientado al futuro? /en/ Revista Política Criminal, No 3, 2007, A2, pp. 1-18, [fecha de consulta: 4 de enero de 2011] Disponible en la Word Wide Web: http://www.politicacriminal.cl 
- $\quad$ Supone un adelantamiento de las barreras de protección, dejando de ser un Derecho de ultima ratio para transformarse en uno de prima ratio;

- Este Derecho penal no solo mira hacia el pasado, al hecho realizado, sino que también al hecho futuro, al que posiblemente se realice, que fundamenta, por ejemplo, las medidas de seguridad contra sujetos peligrosos. Prospectiva en vez de retrospectiva;

- $\quad$ Es el punto de transición entre un Derecho penal del ciudadano y un Derecho penal de lucha o de combate, cuestión altamente discutible;

- Conduce a un relajamiento de las garantías procesales;

A esto, autores como Cornacchia agregan la punición desproporcionada para actos preparatorios o de ejecución imperfecta. No obstante, este mismo autor considera que el DPE sigue siendo Derecho, toda vez que sigue siendo racional, por tanto conoce límites (derecho a la vida, prohibición de esclavitud, torturas o tratamientos inhumanos, principio de tipicidad o prohibición de retroactividad), es judicializado y sigue sujeto a un control de legitimidad ${ }^{15}$.

Esta postura dogmática avanzó de la mano de una verdadera "enemiguización" de la legislación penal moderna, sobre todo después de los atentados terroristas por todos conocidos. Quizás por el mismo hecho -la "enemiguización" - comenzaron a aparecer las críticas a la postura del alemán ${ }^{16}$.

Pero más allá de estas, Jakobs buscó sustentar su posición en la filosofía de autores como Rousseau, Kant o Hobbes, quienes ya habían utilizado, aunque con matices, el concepto de "enemigo". Por lo mismo es conveniente una breve, pero clave, revisión histórica del concepto de enemigo en la filosofía jurídica y en la dogmática penal.

\section{4. ¿Quién es el enemigo?}

Los romanos realizaban una importancia distinción entre inimicus y hostis. El primer concepto aludía al enemigo personal, teniendo un ámbito más restringido. El hostis en tanto era el enemigo público, que era visto como negación absoluta del otro ser, o sea, una especie de no persona, encarnado principalmente por el extranjero, elemento rebosante de hostilidad. Este sujeto estaba fuera de la comunidad, carecía de derechos en lo absoluto. Por lo mismo, no extraña que en muchas culturas antiguas la pena más grave fuera el destierro o la expulsión de la comunidad, ya que

15 Cornacchia, Luigi, La moderna hostis iudicatio. Entre norma y estado de excepción”, en Cancio Meliá, Manuel; Gómez-Jara Díez, Carlos (coords.), Derecho penal del enemigo. El discurso penal de la exclusión, Ed. Edisofer, Madrid, 2006, pp. 447 y ss.

16 Críticas, véase Schilling, obr. cit. pp. 59-61. 
dejaban al expulsado en calidad de extranjero, sin derechos, o sea, un enemigo, pero en estricto rigor, un hostis ${ }^{17}$.

El hostis, particularmente el judicatus, era un enemigo declarado de la república, previa manifestación en ese sentido del Senado, quedando el ex ciudadano en condición semejante a la del esclavo, siendo objeto y sujeto de las penas que les estaban vedadas a los ciudadanos. Si hacemos paralelismos con los usos modernos del concepto enemigo, vemos que, al parecer, esto se acerca más al hostis romano que al inimicus.

Uno de los errores más comunes en las crónicas sobre el Derecho penal del enemigo y sobre Jakobs es identificar en su postura al enemigo con el delincuente. Sin embargo, el autor alemán aquí es muy claro, "No todo delincuente es un enemigo". A contrario sensu, hay delincuentes que sí son enemigos.

Para la determinación del enemigo, Jakobs recurre a la filosofía clásica, amparado al menos en parte en el uso que filósofos como Rousseau o Fichte le dieron al concepto. Para el autor del contrato social, todo malhechor, al atacar el Derecho social, se convierte por sus delitos en rebelde y traidor a la patria, deja de ser miembro de ella al violar sus leyes, y hasta le hace la guerra. El proceso judicial sirve para declarar que este sujeto ha roto el pacto social y ya no es parte del Estado, debiendo ser separado de este mediante el destierro, como simple infractor del pacto, o con la muerte, si es el enemigo. Un enemigo así no es persona moral, sino solo hombre, y entonces el Derecho de guerra consiste en matar al vencido ${ }^{18}$.

Más radical es la postura de Fichte, al afirmar que todo delito excluye el Estado, y que la ejecución del criminal no tendría la naturaleza de una pena, sino de un instrumento de seguridad ${ }^{19}$. Esto, sin duda, está en la misma línea de Jakobs cuando este afirma que el Derecho penal del enemigo es el Derecho penal de las medidas de seguridad. Sin embargo, el propio autor de forma expresa se desmarca del radicalismo de tales posiciones, afirmando que el criminal -no usemos aun el concepto enemigodebe mantenerse dentro del ordenamiento jurídico, tanto para reivindicarse con la sociedad como para reparar el daño causado ${ }^{20}$. En realidad, su línea de pensamiento parece cercana a Hobbes, quien también distingue entre delincuentes y enemigos. Los primeros seguirían siendo ciudadanos, con carta de derechos, sin embargo, aquel

17 Schilling, obr. cit. pp. 85-86. Los romanos distinguían entre el hostis alienígena, que mantenía algún nivel de protección jurídica en el ius gentium, y el hostis judicatus, declarado así por el Senado en virtud de su función de auctoritas. En este último caso, el ciudadano romano que amenazaba la tranquilidad o seguridad de la república vía traiciones o rebelión, podía declararse enemigo, hostis judicatus.

18 Rousseau, Jean Jacques, El contrato social, Ed. EDAF, Madrid, 2007, p. 83.

19 Fichte, Johann Gottlieb, Fundamento del derecho natural según los principios de la doctrina de la ciencia, Centro de Estudios Constitucionales, Madrid, 1994, p. 316.

20 Schilling, obr. cit. p. 91. 
que incurre en la rebelión, en cuanto verdadera recaída al estado de naturaleza, merece el apelativo y la calificación de enemigo ${ }^{21}$, asimilando esto a la guerra de cada uno contra su vecino ${ }^{22}$.

Por otra parte, Kant considera que se puede considerar enemigo a aquel que ha lesionado a otro, estando en un estado de paz, poniendo en peligro este estado. Si un vecino no da garantías de mantener el estado de paz, puede ser hostilizado y tratado como enemigo (hostis, no inimicus). Para estos últimos, habría un Derecho penal del enemigo, coincidiendo con Hobbes, mientras que para el que lesiona o amenaza no de modo persistente -delincuente ocasional- habría un Derecho penal del ciudadano. Para Jakobs, este último mantiene la vigencia de la norma, mientras que el Derecho penal de enemigo combate peligros. El cabecilla u hombre de atrás de una banda organizada de delincuentes es un sujeto peligroso, que debe ser interceptado en un estadio previo a la comisión de un hecho delictivo. Son estados hostiles entre sujetos que se infringen actos de hostilidad (Estado y enemigo).

Schmitt, en tanto, a quien se ha pretendido firmemente vincular ideológicamente con Jakobs, incorpora a su concepto de enemigo -y su alter, el amigo- un componente concreto, aterrizándolo a la realidad de los pueblos, que se agrupan en amigos y enemigos hasta hoy en día, con independencia de cualquier otra valoración económica o moral. Enemigo, para Schimtt, es un conjunto de hombres que se opone, eventualmente, en forma combativa a otro conjunto de hombres ${ }^{23}$. El enemigo es enemigo político, y lo es tal en tanto haya eventualidad de lucha, también en su aspecto concreto -armado- con posibilidad de muerte, y no solamente intelectual. Para el mismo autor, la lucha armada entre unidades políticas organizadas es una guerra, y esta se transforma en civil si esa lucha armada se da en el seno de una unidad organizada. La guerra pasa a ser la realización extrema de la enemistad, y le da sentido al concepto de enemigo.

En estas circunstancias, Schilling apunta un elemento importante respecto a la concepción del enemigo en la actualidad (ya alejado del concepto de enemigo en el estado de naturaleza precivil). El enemigo no tiene identidad, es anónimo, descono-

21 Cabe recordar la contradicción de ideas con Locke, para quien la resistencia al soberano es el ejercicio de un derecho, que el sujeto tiene con anterioridad a la sociedad civil (estado de naturaleza regido por la ley natural). Este mismo sujeto, para Hobbes, es un enemigo, peor que el criminal. Schilling, obr. cit. p. 101.

22 Hobbes no admite la resistencia al soberano, pues importaría reintroducir el bellum omnium contra omnes (la guerra de todos contra todos), y es por eso que quien resiste el poder del soberano no es penado, sino sometido a una contención forzada, ya que no es un delincuente, sino un enemigo. Hobbes, Thomas, Leviatán o la materia, forma y poder de una república eclesiástica y civil, Ed. Universitat de Valencia, Valencia, $2^{\text {a }}$ ed., 1992, pp. 24 y ss.

23 Schmitt, Carl, El concepto de lo político, Ed. Alianza, Madrid, 1999, citado en Schilling, obr. cit. pp. 117 y ss. 
cido, lo que impide tener claridad respecto de quién hay que protegerse, lo que provoca inseguridad. Por ende, la cimentación cognitiva del derecho, sobre todo en la perspectiva funcionalista, depende de la identificación del enemigo ${ }^{24}$.

\section{El concepto de enemigo en Jakobs}

Hay varios asuntos problemáticos respecto a la consideración del enemigo. La filosofía intentó una visión ontológica del mismo, de acuerdo a lo revisado en relación a Rousseau, Hobbes y Fichte, por ejemplo, sin una solución unívoca. En relación a su origen, no hay claridad sobre si el concepto de enemigo ocupado en la actualidad es jurídico o prejurídico. No hay una opinión dominante respecto a si es el Derecho penal el que configura al enemigo o es este el que recalifica al Derecho penal. Se discute incluso si el concepto de enemigo es valorativamente neutro o más bien una calificación peyorativa ${ }^{25}$.

La existencia de una legislación "dura", por Ilamarla de alguna forma, parecería ser un antecedente suficiente para entender que esta especie de "no persona" que sería el enemigo, pasa a ser un ciudadano de tercera clase, o derechamente un no ciudadano, resultando claro el carácter peyorativo del concepto ${ }^{26}$. Al ser un elemento peligroso, el enemigo sería merecedor del rigor de la ley. Sin embargo, Jakobs no le da ese carácter, al hacer una analogía con la disolución de una persona jurídica, por ejemplo, donde esta deja de ser persona distinta de las que lo componen, o bien con el no nacido, que tampoco es persona desde una perspectiva jurídica, pero sí un ser humano. Agrega otras situaciones donde el sujeto que realiza un injusto que genera una legítima defensa o un estado de necesidad es considerado persona justamente para entender que debe soportar el riesgo de su actuar ilegítimo ${ }^{27}$. La diferencia en el caso del hostis es que es este mismo el que, voluntariamente, se excluye del orden social, optando por ser una no persona, o

24 Esto permitiría fundamentar ciertas medidas procesales como las escuchas telefónicas. Schilling, obr. cit. pp. 75 y ss.

25 Es importante delimitar estas u otras cuestiones, como quién es el encargado de decir quién realmente es el enemigo, toda vez que sea cual sea la respuesta tendrá consecuencias importantes en el sistema jurídico. Muñoz Conde, Francisco, obr. cit. p. 816.

26 La distinción amigo-enemigo es política, independiente de su valoración moral (bueno-malo) o económica (rentable-no rentable), por ejemplo. Schilling, obr. cit. pp. 118-119.

27 "Que el agresor retire él mismo su agresión (lo cual a menudo no "costará" mucho) o que otro disponga una defensa que implique una intervención intensiva es, para los efectos que aquí importan, idéntico fenómeno por cuanto él mismo es el competente por los costes: el agresor, quien, por lo tanto, no es excluido, sino precisamente requerido como persona obligada a soportar los costes". Jakobs, Günther, Personalidad y exclusión en Derecho penal, en Montealegre Lynett, Eduardo (coord.) El funcionalismo en Derecho penal. Libro homenaje al profesor Günther Jakobs, Ed. Universidad Externado de Colombia, Bogotá, 2003, pp. 77-78. 
bien derechamente nunca se incluyó en él ${ }^{28}$. El autor alemán se basa en Fichte para asegurar que es posible perder la categoría de ciudadano, pero señala expresamente que él y Rousseau son demasiado abstractos en su separación entre ciudadanos y enemigos ${ }^{29}$, alineándose con Hobbes y Kant, quienes, como se vio, distinguen conceptualmente entre Derecho penal del ciudadano y del enemigo ${ }^{30}$.

Los sujetos que realizan conductas calificadas socialmente como terroristas, o de traición a la patria, o bien los que participan en la delincuencia organizada en general, se marginarían del orden social para transformarse en enemigos por su propia voluntad $^{31}$. No sería el poder público o la ciudadanía siquiera quienes dan esa calificación. Si se asume este punto de vista deberíamos incluir también a la delincuencia relacionada con el tráfico de sustancias ilícitas. Esto es lo que puede extraerse, a priori, de la interpretación de las bases filosóficas de Jakobs ${ }^{32}$.

Para este, el delincuente puede ser considerado, desde la perspectiva del Estado, como personas que al delinquir han cometido un error, por una parte, o como individuos peligrosos a los que hay que impedir que destruyan el ordenamiento jurídico, por otra ${ }^{33}$. Sin embargo, como dice el mismo autor, "no todo delincuente es un adversario por principio del ordenamiento jurídico" ${ }^{34}$.

El emérito de la Universidad de Bonn considera enemigo a aquel que no solo de manera casual delinque, sino que su comportamiento es una muestra palpable y presuntamente verdadera de que ha abandonado el derecho, impidiendo que la comunidad tenga sobre él al menos un mínimo de seguridad cognitiva sobre su comportamiento personal, y que lo manifiesta explícitamente en su conducta ${ }^{35}$. En este rango

28 Por este mismo hecho, para Pérez del Valle, no podría calificarse al Derecho penal del enemigo como Derecho penal de autor Pérez de Valle, Carlos, La fundamentación iusfilosófica del Derecho penal del enemigo. Precisiones sobre la interpretación de Kant /en/ Revista Electrónica de Ciencia Penal y Criminología, N 10-03, 2008 [fecha de consulta: 10 de enero de 2011]. Disponible en la Word Wide Web: http://criminet.ugr.es/recpc/10/recpc10-03.pdf

Jakobs, obr. cit. p. 27.

30 Jakobs, obr. cit. p. 28.

31 El denominador común de todos estos delitos, y otros por cierto, es la reacción frente al poder establecido, por lo que sus hechores podrían calificarse como enemigos. Estos últimos están determinados por la coacción, no por el Derecho. Jakobs, obr. cit. pp. 25-26.

32 Schilling, obr. cit. p. 115. Pérez del Valle se cuestiona, siguiendo a Rousseau, si es posible realmente considerar al tráfico de sustancias ilícitas como validador de enemigos, concluyendo que al tratarse de hechos graves suponen un real quebrantamiento al pacto social, transformándose en sujetos incompatibles con la conservación del Estado. No darían, como dice Jakobs, las señales cognitivas correctas. Pérez del Valle, obr. cit.

33 Jakobs, obr. cit. p. 47.

34 Jakobs, obr. cit. p. 48.

35 Muñoz Conde es ciertamente crítico en esto, afirmando que "una seguridad cognitiva total nunca puede ser garantizada por ningún sistema del tipo que sea". Muñoz Conde, obr. cit. p. 816. 
se encuentran, por ejemplo, el delincuente sexual -se debe suponer que el habitual, no el ocasional-, el delincuente económico, las organizaciones criminales y el tráfico de drogas, que es lo que interesa en estas líneas ${ }^{36}$.

En tanto funcionalista, Jakobs entiende que toda normatividad requiere una base cognitiva, siendo persona solo quien ofrece una garantía cognitiva suficiente de un comportamiento personal conforme a derecho. El enemigo no ofrece ese mínimo, por lo mismo, se transformaría en no persona. Esto, por supuesto, ha sido objeto de fuertes ataques de la doctrina, por ser, aparentemente, atentatorio contra los derechos humanos ${ }^{37}$, al privar de ellos -al menos de forma parcial- a un grupo de sujetos ${ }^{38}$. Esta peligrosidad es puesta de manifiesto por Muñoz Conde, al indicar que cualquier menoscabo a las garantías fundamentales en el proceso penal, propias y básicas del Estado de Derecho, podrán transformarse en un arma efectiva contra el enemigo, pero al mismo tiempo abren la puerta para que pueda colarse subrepticiamente un Derecho penal de carácter autoritario, "tan incompatible con el Estado de derecho como lo son las legislaciones excepcionales de las más brutales dictaduras" ${ }^{\prime 39}$. El enemigo, en la línea de Jakobs y el funcionalismo, es un "ente patológico" o "disfuncional", que defrauda las expectativas normativas de la sociedad de la manera más grave ${ }^{40}$, ergo, el propio sistema social puede proveerse de mecanismos para reafirmar la misma expectativa defraudada.

Jakobs reconoce como un hecho cierto que el legislador penal actual ha pasado a una legislación de lucha contra la criminalidad organizada, la delincuencia económica, el terrorismo y el tráfico de sustancias tóxicas, en la medida de que estos

$36 \quad$ Schilling, obr. cit. p. 133.

37 Sobre el asunto, desde la perspectiva del neoconstitucionalismo teórico y del garantismo, Núñez Leiva, José Ignacio, Un análisis abstracto del Derecho penal del enemigo a partir del constitucionalismo garantista y dignatario /en/ Revista Electrónica Política Criminal, vol. 4, № 8, diciembre, 2009, pp 383-407 [fecha de consulta: 28 de diciembre de 2010]. Disponible en la Word Wide Web: http://www. politicacriminal.cl/Vol_04/n_08/Vol4N8A3.pdf Para el autor, y a propósito del principio de la dignidad humana, "...un constitucionalismo garantista y dignatario, propuestas como el Derecho penal del enemigo presentan notorias incompatibilidades con el concepto de dignidad humana y por tanto, en virtud de lo ya descrito, serían también inconstitucionales. Para alcanzar tal cometido, resta únicamente que constatemos algunas tensiones y/o incompatibilidades entre el Derecho penal de enemigo y la dignidad humana".

38 Schilling, obr. cit. p. 136.

39 Muñoz Conde, obr. cit. p. 817.

40 La dicotomía persona/no persona es equivalente a Derecho penal del ciudadano/Derecho penal del enemigo, de acuerdo a Silva Sánchez, pero que, sin embargo, no se superponen. Esto no sería contradictorio pues un sujeto podría ser no-persona a efectos de la no imputación de responsabilidad, por un lado, y no-persona a los efectos de la inaplicación de ciertos principios tuitivos, en particular, algunas garantías político-criminales materiales y procesales, por otro. Silva Sánchez, Jesús María, Los indeseados como enemigos. La exclusión de seres humanos del status persona, /en/ Revista Electrónica de Ciencia Penal y Criminología, № 09-01, 2007 [fecha de consulta: 10 de Enero de 2011]. Disponible en la Word Wide Web: http://criminet.ugr.es/recpc/09/recpc09-01.pdf 
no prestan las garantías cognitivas mínimas para ser tratados como personas por el Derecho $^{41}$.

Todos estos antecedentes, entonces, permitirían una conclusión inicial de acuerdo al pensamiento jakobsiano: los partícipes (en sentido amplio) de la criminalidad ligada al tráfico de drogas pueden ser considerados como enemigos (siempre desde la perspectiva del autor alemán). Puede afirmarse esto, pues habría una persistencia conductual contraria a los valores sociales de carácter permanente. No se trata de una delincuencia ocasional, sino de conductas permanentes en el tiempo, indefinidas y con clara intención de incrementar su alcance. Esa habitualidad y automarginación condicionan los elementos que impiden las garantías cognitivas requeridas por la ciudadanía para quienes participan de esta actividad.

Sin embargo, y aquí empiezan los problemas a esta conclusión inicial, cabe preguntarse si estas características alcanzan a todos los que participan de este tipo de delincuencia. Una respuesta negativa Ileva a una siguiente conclusión: no todos los partícipes en los delitos de tráfico de drogas son enemigos. Se le dará una vuelta a esta idea.

\section{6. ¿Quién es quién en el tráfico de drogas?}

"Juan Pérez vive con su madre, su cónyuge, su hermana de 15 años y su hija, todas a su cargo. Su vivienda está hipotecada y él no puede hacer frente a esto, ni capital ni intereses. Su hija padece una enfermedad respiratoria, que de no operar urgentemente se transformaría en irremediable. No tiene los medios económicos para la operación. Juan empeña sus bienes y solicita un préstamo formal que le es negado. Pide dinero a un prestamista informal que accede, pero el dinero solo cubre los intereses de la hipoteca, sumado a lo que consigue a través de amistades. Cuando al menos se ha puesto al día con intereses y atrasos, sobreviene la enfermedad de su hija. La operación cuesta $\$ 10.000 .000$, los que puede rebajar, pero en ningún caso a menos de $\$ 2.000 .000$. Le ofrecen transportar droga a otro país, a cambio de una suma de dinero. Dada sus circunstancias, lo piensa y luego acepta. Sin embargo, duda y rompe el pasaporte que le proporcionan para efectuar el viaje. Él y su familia son amenazados por el hecho, por lo que finalmente accede a realizar el viaje" ${ }^{\prime 2}$.

Este Juan Pérez no necesariamente vive en Chile, no necesariamente viaja a España ni tampoco necesariamente se Ilama Juan Pérez. Sin embargo, es probable que quienes

\footnotetext{
41 Jakobs, obr. cit. pp. 40 y ss.

42 El caso es real y ha sido extraído de Martínez-Escamilla, Margarita, Pobreza, estado de necesidad y prevención general: los 'correos de la cocaína' y el Tribunal Supremo español /en/ Revista Internacional de Derecho penal Contemporáneo, Ed. Legis, Nº12, 2005, p. 8.
} 
operen en el sistema se hayan encontrado cien veces con tipos como él. En concreto, este Juan Pérez es un latinoamericano que viajó a España, siendo sorprendido por la policía peninsular. Habiéndose alegado estado de necesidad por parte de la defensa del individuo, el Tribunal Supremo español denegó tal eximente de responsabilidad, dejando fuera incluso la posibilidad de que se le considerara como eximente incompleta. Si cabe o no alegar tal causal de exclusión de responsabilidad penal no es el tema importante en estas ideas, sino que otra cuestión ${ }^{43}$ : ¿Podemos considerar, desde la perspectiva de Jakobs, que Juan Pérez es un enemigo? Porque, claro está, si el TS consideró que Pérez realizó una conducta típica, antijurídica y culpable, ha cometido un delito, y desde la fría perspectiva dogmática es un delincuente, y eso no se discutirá ahora, pero otra cosa distinta es afirmar, o intentar afirmar, que este Pérez es un enemigo.

Parece difícil a simple vista poder calificar a este sujeto, u otro cientos en su situación, con tal apelativo, al menos desde la concepción jakobsiana del mismo. En primer lugar, no estamos en presencia de un sujeto que habitualmente delinque, es decir, cuya actividad principal, cuasi profesión, sea la comisión de delitos de drogas, por mucho que lo haga más de una vez, sobre todo si su actividad principal, o al menos su esperanza, es una vida "normal" (Pérez tiene familia e hijos, y una hipoteca). No parece, como exige la filosofía jakobsiana, un elemento peligroso que pueda destruir el ordenamiento jurídico. Individualmente eso sería impensable, casi como destruir el medio ambiente tirando un papel a la calle, y su efecto cumulativo es altamente cuestionable en casos análogos, al menos como fundamento de la intervención penal al nivel del DPE.

No existe de parte de Juan Pérez una reacción frente al poder establecido, sino más bien un actuar de manera que el error pase desapercibido para seguir siendo parte del sistema social ("gano lo que necesito para la hipoteca -LA HIPOTECA-, y me salgo"). Este sujeto, habiendo cumplido la pena o incluso con cualquier sustitutivo que en abstracto pudiera comprenderse, parece perfectamente compatible con la conservación del Estado, al no tener la envergadura de un adversario del ordenamiento jurídico.

Es posible creer, sin hacer grandes elucubraciones, que la comunidad puede tener sobre su comportamiento al menos un mínimo de seguridad cognitiva y una proyección mínimamente esperable de reinserción al derecho, sobre todo al representar con su actuar una mínima muestra de respeto a los valores sociales (en el caso de Juan, mantención de la familia y la salud de los críos). Es esperable a su vez que, al ocurrir un hecho propio de la vida social -encontrar un trabajo "legal", por ejemplono haya persistencia en el actuar delictivo.

43 Martínez Escamilla realiza un interesante análisis sobre el rechazo que el Tribunal Supremo español ha realizado en forma sistemática a la aplicación del estado de necesidad, por razones dogmáticas y político-criminales, que la autora considera poco consistentes. Martínez-Escamilla, obr. cit. pp. 8 y ss. 
Siendo más concreto, Juan Pérez puede estar perfectamente representado por los ciudadanos de países vecinos que ingresan al país con droga bajo la promesa de sumas de dinero mínimas (frente al riesgo) pero importantísimas para ellos. O bien la gran cantidad de mujeres-madres que cumplen condena en nuestros recintos penitenciarios por delitos de la Ley 20.000 o sus antecesoras. Y peor aún, quienes cumplen con ambos perfiles ${ }^{44}$.

Juan Pérez o sus émulos han actuado contrariando una norma secundaria prohibitiva, pero no deberían ellos ser considerados enemigos de acuerdo a los parámetros de Jakobs, autor que, como ya se ha visto, distingue claramente entre delincuentes y enemigos. Supra se mencionaba la situación del exceso en la legítima defensa o la culpabilidad disminuida, situaciones donde existe un delito, pero el sujeto sigue siendo persona, no enemigo ${ }^{45}$. Es más, Jakobs deja entrever incluso que no todo enemigo debe ser combatido, sino que a algunos deben ser estimulados por el Derecho penal, otros desconectados y solo los casos más graves serían objeto de combate, o sea, de Derecho penal de enemigos $^{46}$.

Ahora, diferente parece ser el caso de los grupos o asociaciones delictivas en el narcotráfico, pues, a diferencia de Juan Pérez, parecen cumplir al menos algunos de los elementos que los harían merecedores de la calificación de enemigos.

Es necesario recordar que, en el pensamiento de Jakobs, aquel delincuente que ya no presta garantías cognitivas sobre su personalidad se transforma en enemigo, lo que sucede cuando aquel se ha consagrado de un modo tácito y duradero a la delincuencia, lo que puede hacer a través de una conducta, como el delincuente sexual; de su medio de vida, como la criminalidad económica, el crimen organizado o la delincuencia relacionada con los estupefacientes; o bien a través de su vinculación a una organización, como sería el caso del terrorismo y, de nuevo, el crimen organizado y la delincuencia de estupefacientes ${ }^{47}$. A estos, en cualquiera de las hipótesis, se les combate ${ }^{48}$. La razón de esto radica en que el crimen organizado, tanto en drogas como en otros "mercados", es capaz de desestabilizar los sistemas político y económico $^{49}$, transformándose, por usar jerga de Beck, en un inmenso foco de riesgo para la sociedad moderna.

44 Estadísticas de la población penitenciaria al 2008, véase en Paz Ciudadana, Boletín Estadístico, [fecha de consulta: 10 de enero de 2011]. Disponible en la Word Wide Web: http://www.pazciudadana.cl/ docs/pub_20100414120800.pdf

45 Jakobs, obr. cit. p. 82.

46 Jakobs, obr. cit. p. 86.

47 Jakobs, obr. cit. pp. 86-87.

48 Lo ejemplifica Jakobs con la propia nomenclatura usada en Alemania a propósito de la legislación denominada "leyes de combate". Jakobs, obr. cit. p. 85.

49 Sánchez García de la Paz, Isabel, La criminalidad organizada. Aspectos penales, procesales, administrativos y policiales, Ed. Dykinson, Madrid, 2005, p. 63. 
De lo dicho en la primera parte del párrafo anterior puede desprenderse que la delincuencia relacionada con las drogas y los estupefacientes admite ciertas clasificaciones o divisiones. El tamaño de la agrupación, su peligrosidad, alcances o formas de vida podrían ser los criterios que permitan sostener tal escisión. El mismo autor toma como ejemplo las bandas de ladrones alemanas en los años 30, que ya eran combatidas como enemigos. Sin embargo, no podemos negar que dichas bandas, como nuestros históricos Pincheira, no alcanzan la envergadura de las actuales organizaciones delictivas ${ }^{50}$.

La criminalidad organizada en general, y el narcotráfico en particular, se caracterizan, entre otros elementos, por su internacionalidad, su organización extremadamente compleja, jerarquizada como una verdadera empresa transnacional de carácter delictivo, apoyo logístico con abundantes recursos tecnológicos, humanos, científicos y logísticos, profesionales especializados y con organigramas en extremo parecidos al de entidades militares o policiales ${ }^{51}$. La doctora Zúñiga Rodríguez distingue las características de esta criminalidad organizada en dos grupos: las esenciales y las contingentes $^{52}$.

Las primeras son tres: la organización, el fin de lucro (salvo el terrorismo) y la comisión de delitos graves. Las contingentes son: la búsqueda de impunidad, el secretismo, las vinculaciones con el mundo empresarial y la política, la actividad internacional y la búsqueda del dominio del mercado.

La gran criminalidad del narcotráfico cumple prácticamente con todas estas características, siendo sin duda arquetípica dentro del crimen organizado. Y ese perfil, al menos desde una perspectiva general del problema, encaja con lo exigido por Jakobs para hablar de enemigos. A saber:

- Son un grupo que se constituye como elemento de alto peligro para el ordenamiento jurídico, y para los mismos agentes del sistema de justicia. Basta con ver la situación de Colombia y México, con jueces, fiscales o policías amenazados o derechamente muertos por estas mafias ${ }^{53}$.

50 Jakobs, obr. cit. p. 87. Otros ejemplos en España y Latinoamérica, Rodríguez, Laura, Criminalidad organizada y sistema de Derecho penal. Contribución a la determinación del injusto penal de organización criminal, Ed. Comares, Granada, 2009, pp. 38 y ss.

51 Lagos, Carlos, Políticas gubernamentales contra la criminalidad organizada, en Politoff, Sergio; Matus, Jean Pierre (coords.). Gran criminalidad organizada y tráfico ilícito de estupefacientes, Ed. Jurídica ConoSur, Santiago, 2000, p. 39.

52 Zúñiga Rodríguez, obr. cit. pp. 126 y ss.

53 Un pequeño apunte en Ríos, Viridiana, ¿Quién se vuelve narco y por qué? El Perfil del narcotraficante Mexicano [fecha de consulta: 30 de diciembre de 2010]. Disponible en la Word Wide Web: http:// www.gov.harvard.edu/files/uploads/Rios_EstePais_DealersS.pdf. 
- Hay una opción voluntaria por excluirse del sistema social -aunque esto sea casi un imposible en forma absoluta-. Un vistazo a lo que ocurre con los piratas somalíes demuestra esto. Como expresaba un reportaje de la BBC, estos barbarrojas modernos "se casan con las chicas más hermosas, tienen los mejores autos, las casas más grandes y las últimas armas", tienen sus propios sistemas de defensa y de resolución de conflictos. En resumen, prácticamente prescinden del Estado y se constituyen en una nueva organización social ${ }^{54}$.

- Lo anterior a su vez representa una fuerte reacción al poder establecido, siendo prácticamente incompatibles con la conservación del Estado.

- Su persistencia a contrariar los valores sociales mínimos conduce a que la sociedad no pueda tener sobre su comportamiento un mínimo de seguridad cognitiva, al demostrar un abandono casi completo del Derecho.

Las grandes mafias que trafican drogas repiten estas características, con matices obviamente, pero cumplen con los parámetros jakobsianos. Por ende, correrían la misma suerte: enemigos.

El problema sería la calificación de enemigos o no para la delincuencia asociada de pequeño o mediano tamaño. Algo así como "los Macaya", "los Carépelota" o "El Clan Gálvez Calderón" (conocidas bandas del hampa chilena), grupos cuyo núcleo central bordea la veintena de personas, unidos por vínculos familiares y cuyas redes alcanzan transversalmente varios sectores de las grandes ciudades. Si bien se cumple con el supuesto básico de estar organizados en grupos peligrosos, no parecen cumplir con los demás requisitos del enemigo de Jakobs, o si lo hacen es en menor escala ${ }^{55}$. No pondrían en jaque al ordenamiento jurídico en su generalidad, pero sí es posible ver en su conducta y forma de vida una dañosidad manifiesta frente a los operadores jurídicos -fiscales, policías-.

Hay una exclusión parcial del sistema social en cuanto participan de una o más de sus instituciones. Hay una reacción al poder establecido -basta ver los problemas que tiene la policía para ingresar a ciertos sectores poblacionales tomados por las

54 [fecha de consulta: 5 de noviembre de 2010]. Disponible en la Word Wide Web: http://news.bbc.co.uk/ hi/spanish/international/newsid_7735000/7735045.stm

55 Clara es la idea, como lo apunta Sánchez García de Paz, de que quienes operan en el mercado de la droga terminan controlando, desde un mercado ilegal, ciertos sectores económicos legales, a través de la violencia o la corrupción, preferentemente. Por desgracia, parecen no existir estudios empíricos que demuestren si el mediano tráfico de estupefacientes tiene realmente un control sobre estos agentes legales (políticos, funcionarios públicos, etc.), o si más bien esto queda restringido a los grandes grupos. Sánchez García de la Paz, obr. cit. p. 45. En la doctrina nacional, véase Barra Gallardo, Nancy, Fenómenos de corrupción en el mundo actual. Relación entre lo público y lo privado, Ed. LegalPublishing, Santiago, 2007, pp. 77 y ss. 
bandas- pero en su magnitud no parecen poner en peligro la existencia y conservación del Estado, sino solamente dificultar su acción en ciertos ámbitos de la vida social. Finalmente, hay una subutilización de algunos valores sociales como la familia y la lealtad, pero una transgresión a otros absolutamente básicos como la vida, la seguridad o la seguridad. Esto último pone en jaque el mínimo de seguridad cognitiva exigido por Jakobs.

Estos grupos intermedios parecieran estar a medio camino entre el delincuente y el enemigo jakobsiano, por lo que es difícil justificar el DPE en su extremo más crudo. Sin embargo, y como señalaba supra, el mismo Jakobs deja entrever que no todo enemigo debiera ser combatido -o sea, ser objeto del DPE-, sino que algunos podían ser estimulados o desconectados (no aclara qué quiere decir con esto). Aquí podría estar el espacio para los macayas o care'pelotas. Los juanes pérez seguirían considerándose delincuentes para el alemán, siendo las grandes organizaciones criminales el verdadero enemigo.

\section{Conclusiones}

Estas ideas no avalan ni pretende avalar al DPE, sino solo discurrir sobre ciertos aspectos conceptuales importantes de la propuesta de Jakobs. Es principalmente una discusión en sede político-criminal, tendiente a clarificar conceptos usados muchas veces sin mayores escisiones, pero que requieren un análisis más allá de lo superficial ¿Para qué? Lo respondo con palabras de Muñoz Conde, quien frente a la pregunta de si, al aceptarse de Ileno un DPE, implicaría la inclusión de la tortura como medio de investigación o la pena de muerte aplicada por tribunales militares de excepción, señala: "probablemente más de uno ya estará buscando argumentos jurídicos que avalen estas posibilidades. Sin duda, podrá encontrarlos en alguna construcción doctrinal..." ${ }^{56}$.

\section{Agradecimientos}

Hago públicos mis especiales agradecimientos a Nadia Rojas Riquelme, por sus aportes en las correcciones de este trabajo, a quien confié por su minuciosidad, responsabilidad y dedicación al asumir cada una de las empresas que se le encomiendan.

56 Muñoz Conde, obr. cit. p. 818. 


\section{Bibliografía}

\section{Libros}

Barra Gallardo, Nancy, Fenómenos de corrupción en el mundo actual. Relación entre lo público y lo privado, Ed. LegalPublishing, Santiago, 2007.

Fichte, Johann Gottlieb, Fundamento del derecho natural según los principios de la doctrina de la ciencia, Centro de Estudios Constitucionales, Madrid, 1994.

García Martín, Luis, El horizonte del finalismo y el Derecho penal del enemigo, Ed. Tirant lo Blanch, Valencia, 2005.

Garland, David, La cultura del control. Crimen y orden social en la sociedad contemporánea, Ed. Gedisa, Barcelona, 2005.

Hobbes, ThOmAs, Leviatán o la materia, forma y poder de una república eclesiástica y civil, Ed. Universitat de Valencia, Valencia, $2^{a}$ ed., 1992.

Jakobs, Günther; Cancio Meliá, Manuel, Derecho penal del enemigo, Ed. Civitas, Madrid, 2001.

JAKOBS, Günther, Sociedad, norma y persona en una teoría de un Derecho penal funcional, Ed. Civitas, Madrid, 1996.

Luhmann, Niklas, Complejidad y modernidad de la unidad a la diferencia, Ed. Trotta, Madrid, 1998.

Luhmann, Niklas, Sociedad y sistema, la ambición de la teoría, Ed. Paidós, Barcelona, 1997.

Martínez-Escamilla, Margarita, Pobreza, estado de necesidad y prevención general: los 'correos de la cocaína' y el Tribunal Supremo español /en/ Revista Internacional de Derecho penal Contemporáneo, Ed. Legis, N¹2, 2005.

Montealegre Lynett, Eduardo (coord.) El funcionalismo en el Derecho penal. Libro homenaje al profesor Günther Jakobs, Ed. Universidad Externado de Colombia, Bogotá, 2003.

Muñoz Conde, Francisco, Edmund Mezger y el Derecho penal de su tiempo, Ed. Tirant lo Blanch, Valencia, $4^{\mathrm{a}}$ ed. 2003.

NúÑez Leiva, José IGNACIO, Un análisis abstracto del Derecho penal del enemigo a partir del constitucionalismo garantista y dignatario /en/ Revista Electrónica Política Criminal, vol. 4, N 8, diciembre, 2009, pp 383-407 [fecha de consulta: 28 de diciembre de 2010]. Disponible en: http://www.politicacriminal.cl/Vol_04/n_08/ Vol4N8A3.pdf

Octavio de Toledo y Ubieto, Emilio, et al., Estudios penales en recuerdo del profesor Ruiz Antón, Ed. Tirant lo Blanch, Valencia 2004. 
Paz Ciudadana, Boletín Estadístico, [fecha de consulta: 10 de enero de 2011] Disponible en: http://www.pazciudadana.cl/docs/pub_20100414120800.pdf

Pérez de Valle, Carlos, La fundamentación iusfilosófica del Derecho penal del enemigo. Precisiones sobre la interpretación de Kant /en/ Revista Electrónica de Ciencia Penal y Criminología, N 10-03, 2008 [fecha de consulta: 10 de enero de 2011]. Disponible en: http://criminet.ugr.es/recpc/10/recpc10-03.pdf

Peset, Mariano; Peset, José Luis, (Estudio preliminar), Lombroso y la escuela positivista italiana, Ed. C.S.I.C., Madrid, 1975.

Politoff, Sergio, Matus, Jean Pierre (coords.) Gran criminalidad organizada y tráfico ilícito de estupefacientes, Ed. Jurídica ConoSur, Santiago, 2000.

Ríos, VIRIDIANa, ¿Quién se vuelve narco y por qué? El Perfil del narcotraficante Mexicano [fecha de consulta: 30 de diciembre de 2010]. Disponible en: http://www. gov.harvard.edu/files/uploads/Rios_EstePais_DealersS.pdf

Rodríguez, Laura, Criminalidad organizada y sistema de Derecho penal. Contribución a la determinación del injusto penal de organización criminal, Ed. Comares, Granada, 2009.

Rousseau, Jean Jacques, El contrato social, Ed. EDAF, Madrid, 2007.

Sánchez García de la Paz, Isabel, La criminalidad organizada. Aspectos penales, procesales, administrativos y policiales, Ed. Dykinson, Madrid, 2005.

Schilling Fuenzalida, Mario, El nuevo Derecho penal del enemigo, Ed. Librotecnia, Santiago, 2010.

Schmitt, Carl, El concepto de lo político, Ed. Alianza, Madrid, 1999.

Silva Sánchez, Jesús María, La expansión del Derecho penal, Ed. Civitas, Madrid, $2^{\mathrm{a}}$ ed. revisada y ampliada, 2001.

Silva Sánchez, Jesús María, Los indeseados como enemigos. La exclusión de seres humanos del status persona, /en/ Revista Electrónica de Ciencia Penal y Criminología, N09-01, 2007 [fecha de consulta: 10 de enero de 2011]. Disponible en: http://criminet.ugr.es/recpc/09/recpc09-01.pdf

Velásquez Velásquez, Fernando (coord.) Derecho penal liberal y dignidad humana. Libro homenaje al Doctor Hernando Londoño Jiménez, Ed. Temis S. A., Bogotá, 2005.

Víquez, Karolina, Derecho penal del enemigo ¿Una quimera dogmática o un modelo orientado al futuro? /en/ Revista Política Criminal, No 3, 2007, A2, p. 1-18 [fecha de consulta: 4 de enero de 2011]. Disponible en: http://www.politicacriminal.cl 